\title{
DAMAGE DETECTION AND SIZE QUANTIFICATION OF FML WITH THE USE OF NDE
}

\author{
Krzysztof Dragan ${ }^{1}$ \\ Lukasz Kornas ${ }^{1}$ \\ Michal Kosmatka ${ }^{1}$ \\ Andrzej Leski ${ }^{1}$ \\ Michal Salaciński ${ }^{1}$ \\ Piotr Synaszko ${ }^{1}$ \\ Jarosław Bieniaś ${ }^{2}$ \\ Air Force Institute of Technology, Warsaw, Poland ${ }^{\mathbf{1}}$ \\ Lublin University of Technology, Lublin, Poland ${ }^{2}$
}

\begin{abstract}
Composite materials have been developed in recent years. A new generation of structural composite materials for advanced aircraft is Fibre Metal Laminates (FML). They are hybrid composites consisting of alternating thin layers of metal sheets and fiber-reinforced composite material. FMLs have both low weight and good mechanical properties (high damage tolerance: fatigue and impact characteristics, corrosion and fire resistance).

Quality control of materials and structures in aircraft is an important issue, also for Fibre Metal Laminates. For FML parts, a 100\% non-destructive inspection for internal quality during the manufacturing process is required. In the case of FML composites, the most relevant defects that should be detected by non-destructive testing are porosity and delaminations.

In this paper, a number of different non-destructive methods for the inspection of Fibre Metal Laminates were studied. The possibility of quality control of manufactured FML laminates detection of defects as well as the procedures and processes are presented and discussed.
\end{abstract}

Keywords: fibre metal laminates, composites, non-destructive testing.

\section{INTRODUCTION}

Composite materials are now widely applied in aerospace structures. A new generation of structural composite materials for advanced aircraft is Fibre Metal Laminates (FML). The often used metal for FML is aluminium, and the fibers are glass, Kevlar or carbon. FML with glass fibers is called GLARE (GLass ALuminum REinforced), with Kevlar fibers is called ARALL (ARamid-fibre-reinforced- polymer/ALuminum Laminates) and with carbon fibers is called CARAL (CArbon Reinforced Aluminum Laminates). Composite FML have been selected for application in aircraft structures because they have both low weight and good mechanical properties (high damage tolerance: fatigue and impact characteristics, corrosion and fire resistance). FML composites can be either in the form of laminar structures or sandwich structures[1]. 

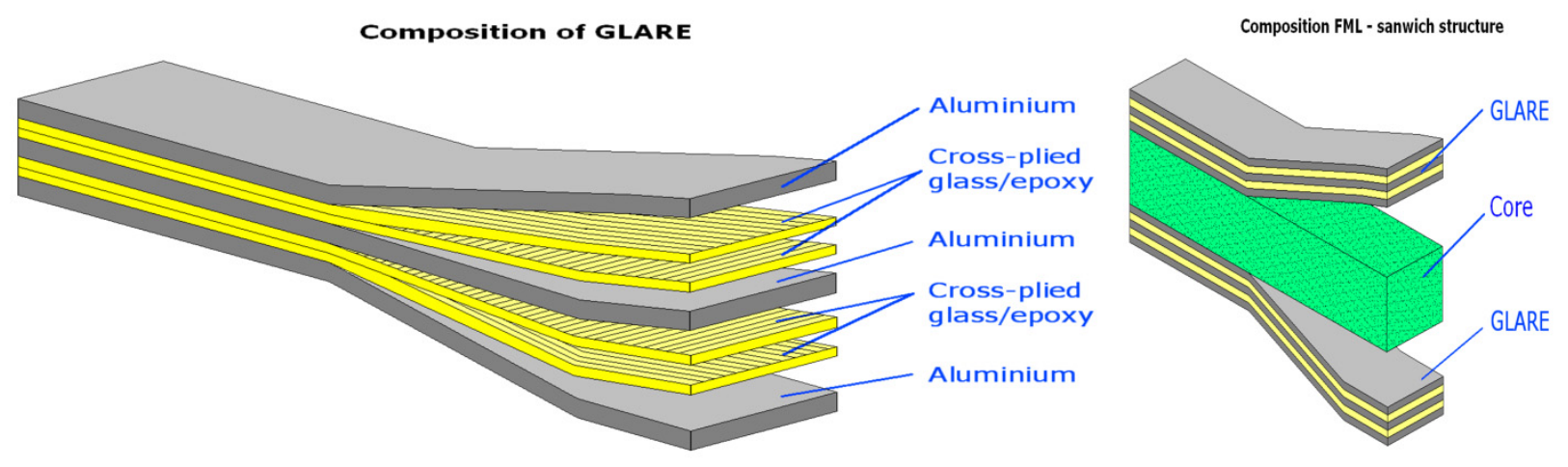

Fig. 1. Types of FML structures

An FML layered structure is particularly susceptible to the detachment of the layers. Also, delaminations and cracks in the aluminum layers may occur as a result of stress $[2,3,4]$.

Quality control of materials and structures in aircraft is an important issue, also for FML laminates. For FML parts, a 100\% non-destructive internal quality inspection during the manufacturing process is required. In the case of FML composites, the most relevant defects that should be detected by non-destructive testing are porosity and delaminations as well as cracks in the aluminum layer.

For the purpose of monitoring the integrity of an FML structure, a combination of multiple NDT methods is commonly used [1]:

- Visual (especially for inspections of fasteners and curved panels e.g. C \& D checks of aircraft);

- Eddy Current (this technique is the best for crack detection in paramagnetic materials such as aluminum alloy);

- Ultrasonic (capable of detecting the following types of damage: disbonds, delaminations, foreign object inclusions and impact damage);

- Thermography (capable of detecting the following damages: disbonds, delaminations, foreign object inclusions and impact damage).

\section{RESULTS AND DISCUSSION}

The non-destructive FML testing was made for the GLARE structures. For the sample no.1 in the aluminum layer and for the sample no.2 in the laminate layer, the cirle shape defects of different diameters were made. Figure 2 shows the results of the $\mathrm{C}$-scan inspection of a single Ultrasonic sensor, Phased Array, Eddy Current and Pulsed Thermography. 

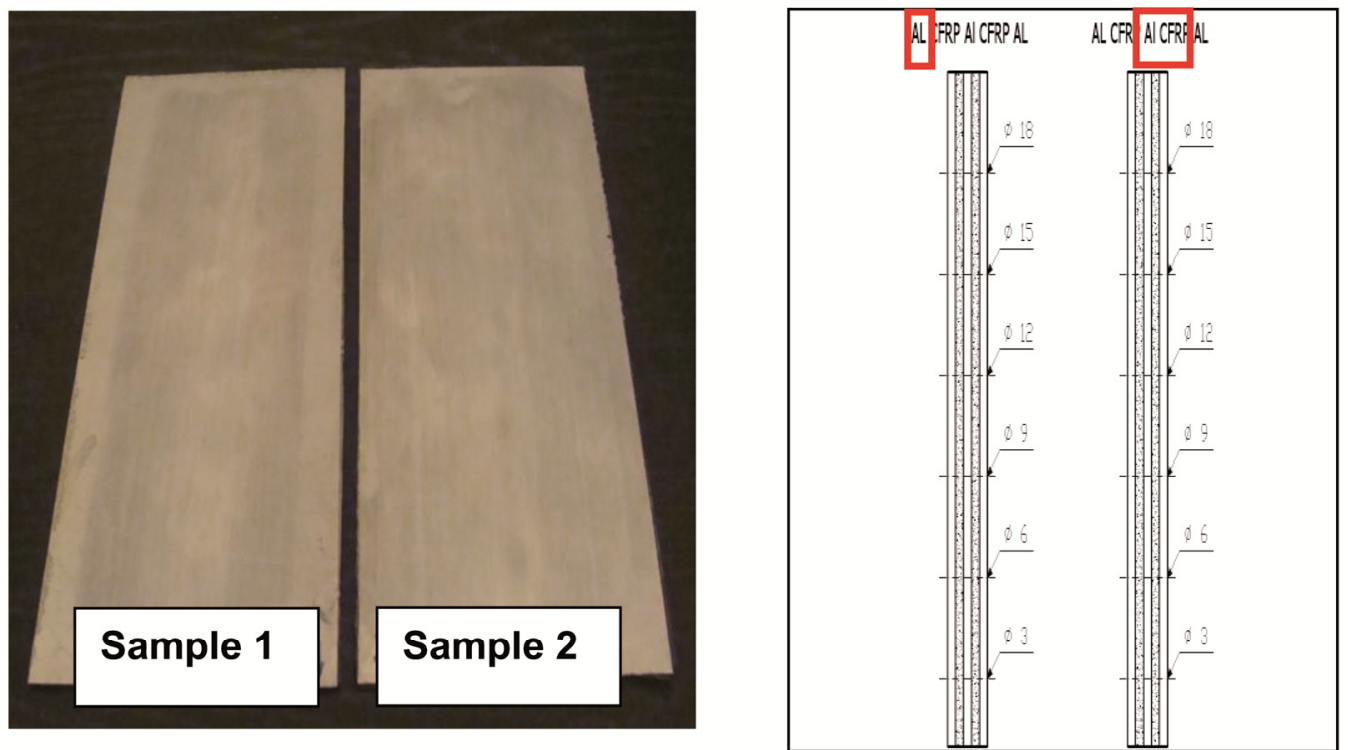

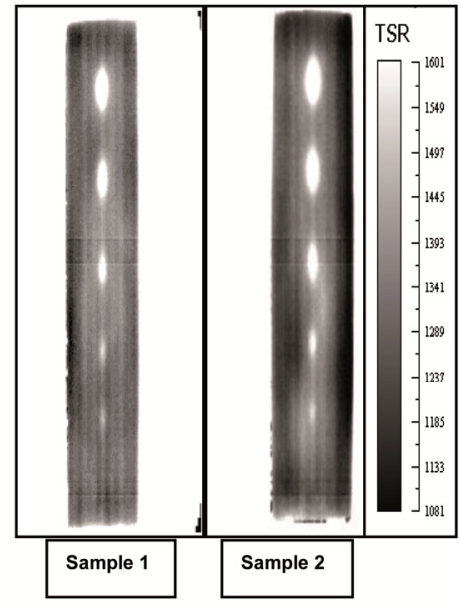

Pulsed Thermography

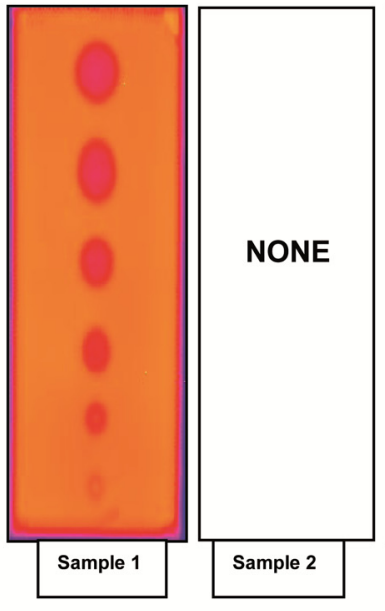

Eddy Current

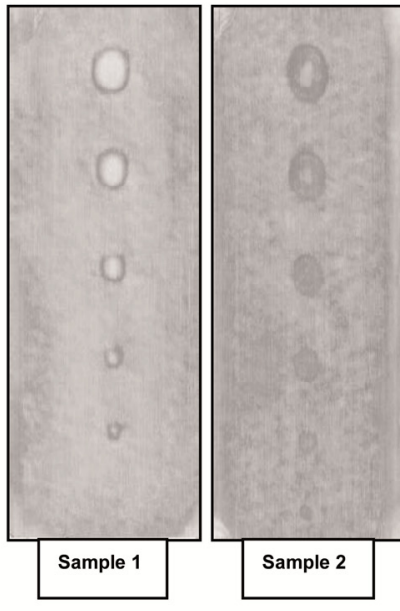

Single sensor UT

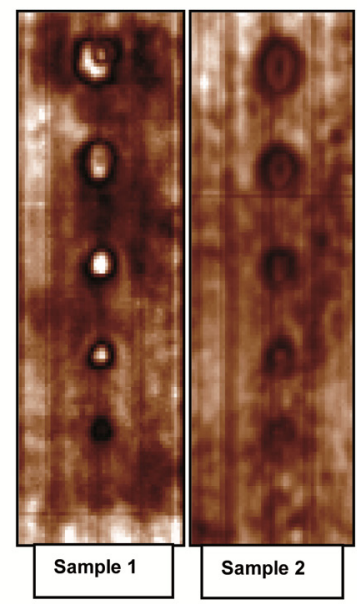

Phas ed Array UT

Fig. 2. NDT results of Fibre Metal Laminate inspection

Analysis of the results enabled to determine the detection of defects by various NDT methods and to determine the accuracy of these methods.

Figure 3 shows defect size estimation determined by various NDT methods for the prepared specimens.
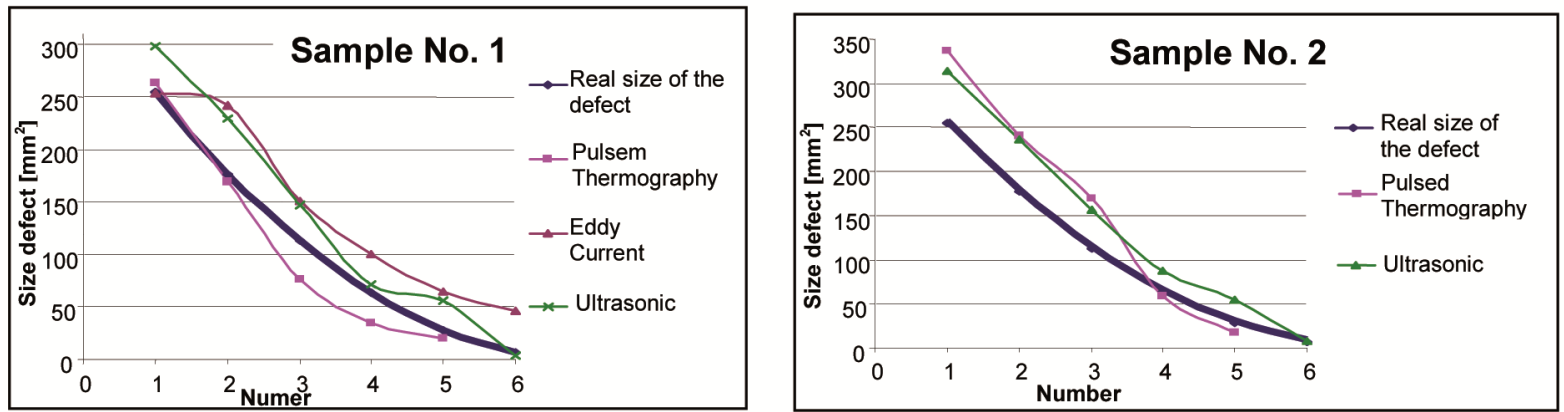

Fig. 3. Defect sizes determined by various NDT methods 
The discrepancy between the size of the defect made in the specimen before the inspection and the size detected by the inspection with use of the ultrasonic method is due to the transmitter diameter and the beam divergence as well as the level of setting the threshold gates.

The sizes obtained using the eddy current method are also different from the actual sizes because of the so called "edge effect" characteristic for this method.

Pulsed thermography method gave results in size estimation similar to the designed but it was not possible to detect all existing defects.

The samples were examined by the ultrasound method and then evaluated independently by five experts. The results were used to determine the PoD curve (Fig.4) [5].

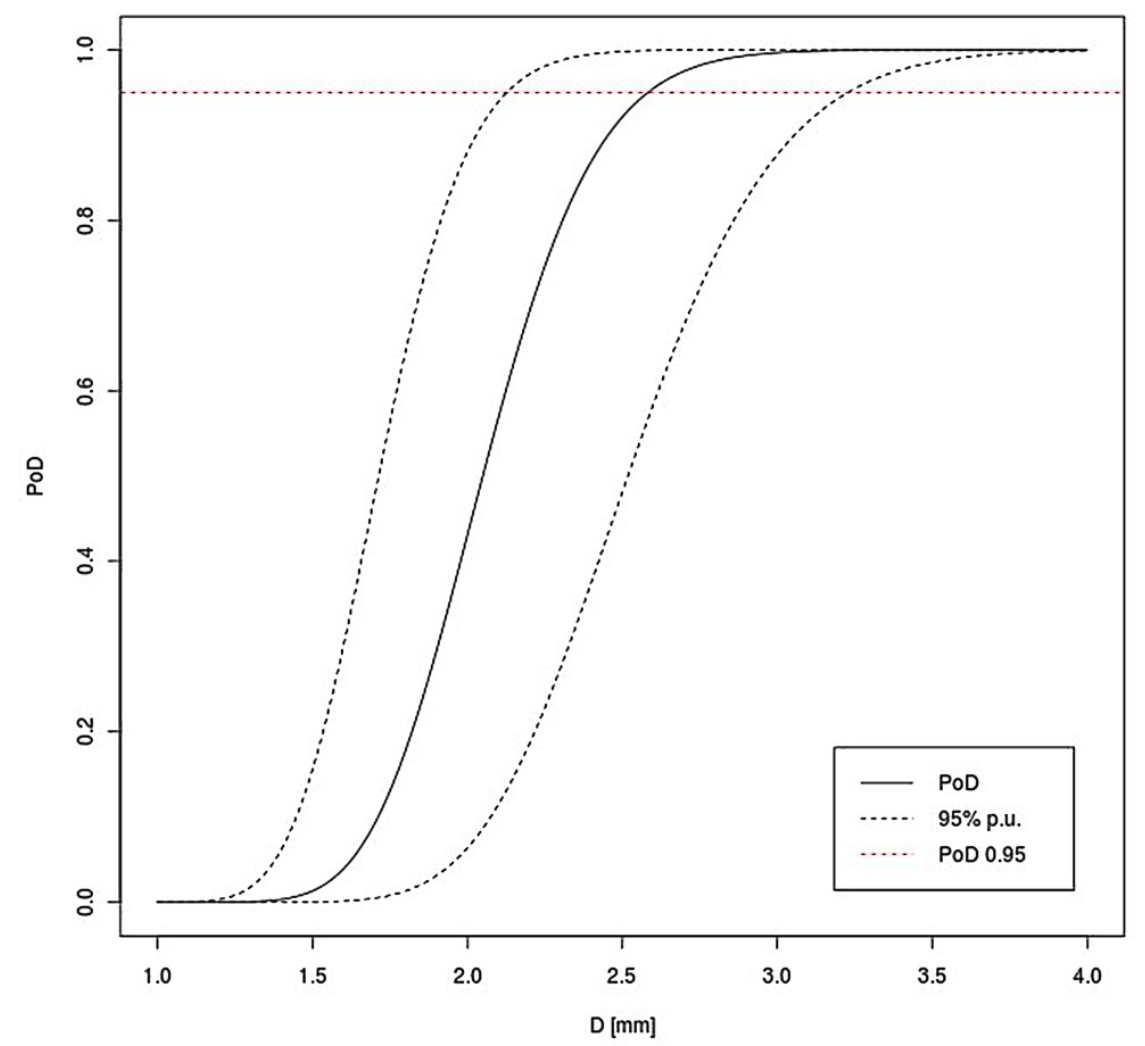

Fig. 4. PoD curve for ultrasonic method, where $D$ - diameter of the damage;

PoD - Probability of Damage Detection;95\% p.u. confidence interval for PoD curve; PoD 0.95 - 95\% level of the damage detection.

In the first step, the linear regression model was tailored [5]:

$$
\log \hat{a}_{i}=\alpha \log a_{i}+\beta+\varepsilon_{i},
$$

where $\hat{a}_{i}$ equals the estimated size of the damage, $a_{i}$ the real size of the damage, $\varepsilon_{i}$ random measurement error. The use of least square method yielded the following model parameters estimators:

$$
\alpha=1.095 \pm 0.033, \quad \beta=-0.16 \pm 0.14
$$

The probability of the delamination detection of the damage size of the determined D size is given in the equation:

$$
P o D(a)=P(\hat{a}>T)=\phi\left(\frac{\log T-\alpha \log \pi\left(\frac{D}{2}\right)^{2}-\beta}{\sigma}\right),
$$


where $\mathrm{T}$ is the selected threshold level, $\sigma$ standard deviation of the measurement error $\varepsilon, \phi$ cumulative function of the standard normal distribution. Based on the confidence intervals or the parameters $\alpha, \beta$ it is possible to determine the $95 \%$ confidence interval for the given above $\operatorname{PoD}(a)$ value. Moreover, the value $a_{0.95}$, for which $\operatorname{PoD}\left(a_{0.95}\right)=0.95$, was given based on:

$$
\log \left(a_{0.95}\right)=\frac{\log T-\beta}{\alpha}+\frac{\sigma}{\alpha} u_{0.05},
$$

where $u_{0.05}$ means $95 \%$ quintile of the standard normal distribution. Estimated diameter size of the damage with $95 \%$ detectability equals:

$$
D_{0.95}=2.58 \mathrm{~mm}
$$

\section{CONCLUSIONS}

The article highlights the inspection issues for the diagnostics of FML structures with the nondestruction methods based on the GLARE specimens. The use of NDT methods (ultrasonic, eddy current, thermography) gives the possibility to detect damage in FML composites. Ultrasound and pulsed thermography methods allow for the detection of defects in the entire volume of the material (detecting defects in the layers of aluminum and glass fibers).

Eddy current method can only be used to detect defects in the aluminum layers. The results of ultrasonic testing were used to create the PoD curve, which estimates the detection of defects possibility in FML for a 95\% confidence interval. This approach enables to determine the accuracy of NDT methods.

The work was supported by the Operational Programme - Innovative Economy (IE OP) financed from the European Regional Development Fund - Project "Modern Material Technologies in Aerospace Industry", No. POIG.01.01.02-00-015/08-00.

\section{REFERENCES}

[1] K. Dragan, J. Bieniaś, M. Sałaciński, P. Synszako (2011). Inspection methods for quality control of fibre metal laminates in aerospace components. Composites. No 2, 130-135.

[2] G. Reyes Villanueva, W.J. Cantwell (2004). The high velocity impact response of composite and FML-reinforced sandwich structures. Composites Science and Technology. 64(1), 35-54.

[3] S.H. Song, Y.S. Byun, T.W. Ku, W.J. Song, J. Kim, B.S. Kang (2010). Experimental and Numerical Investigation on Impact Performance of Carbon Reinforced Aluminum Laminates. Journal of Materials Science \& Technology. 26(4), 327-332.

[4] Edson Cocchieri Botelho, Rogério Almeida Silva, Luiz Cláudio Pardini, Mirabel Cerqueira Rezende (2006). A review on the development and properties of continuous fiber/epoxy/aluminum hybrid composites for aircraft structures. Materials Research. 9(3), 247-256.

[5] Instytut Techniczny Wojsk Lotniczych. (2011). Ocena możliwości diagnostycznych poszczególnych metod do wybranych rodzajów uszkodzeń. Określenie wykrywalności i dokładności poszczególnych metod, Warszawa. (Sprawozdanie Nr 146/31/2011). 